BMJ Open

Diabetes

Research

$\&$ Care

\title{
Frequency of self-monitoring of blood glucose in relation to weight loss and A1C during intensive multidisciplinary weight management in patients with type 2 diabetes and obesity
}

\author{
Shaheen Tomah, ${ }^{\oplus 1}$ Noor Mahmoud, ${ }^{1}$ Adham Mottalib, ${ }^{\oplus 1,2}$ David M Pober, ${ }^{1}$ \\ Mhd Wael Tasabehji, ${ }^{1}$ Sahar Ashrafzadeh, ${ }^{1}$ Osama Hamdy ${ }^{1}$
}

To cite: Tomah S, Mahmoud N, Mottalib A, et al. Frequency of self-monitoring of blood glucose in relation to weight loss and $\mathrm{A} 1 \mathrm{C}$ during intensive multidisciplinary weight management in patients with type 2 diabetes and obesity. BMJ Open Diab Res Care 2019;7:e000659. doi:10.1136/ bmjdrc-2019-000659

Data from this work were presented at the 78th Scientific Sessions of the American Diabetes Association, 22-26 June 2018, Orlando, Florida, USA.

Received 1 February 2019 Revised 1 July 2019 Accepted 12 July 2019

Check for updates

\section{(c) Author(s) (or their} employer(s)) 2019. Re-use permitted under CC BY-NC. No commercial re-use. See rights and permissions. Published by BMJ.

${ }^{1}$ Section on Clinical, Behavioral and Outcomes Research, Joslin Diabetes Center, Harvard Medical School, Boston, Massachusetts, USA 2Department of Medicine, Lahey Hospital and Medical Center, Burlington, Massachusetts, USA

Correspondence to Dr Shaheen Tomah; shaheen.tomah@joslin.harvard. edu

\section{ABSTRACT}

Objective We evaluated the relationship between frequency of self-monitoring of blood glucose (SMBG) and body weight, $\mathrm{A} 1 \mathrm{C}$, and cardiovascular risk factors in patients with type 2 diabetes (T2D) and obesity enrolled in a 12-week intensive multidisciplinary weight management (IMWM) program.

Research design and methods We conducted a retrospective analysis of 42 patients who electronically uploaded their SMBG data over 12 weeks of an IMWM program and divided them into tertiles based on their average frequency of SMBG per day. Mean (range) SMBG frequencies were 2.3 (1.1-2.9) times/day, 3.4 (3-3.9) times/day, and 5 (4-7.7) times/day in the lowest, middle, and highest tertiles, respectively. Anthropometric and metabolic parameters were measured at baseline and after 12 weeks of intervention.

Results Participants in the highest tertile achieved a median change (IQR) in body weight of $-10.4 \mathrm{~kg}(-7.6$ to $-14.4 \mathrm{~kg})$ compared with $-8.3 \mathrm{~kg}(-5.2 \mathrm{to}-12.2 \mathrm{~kg})$, and $-6.9 \mathrm{~kg}(-4.2$ to $-8.9 \mathrm{~kg})$ in the middle and lowest tertiles, respectively ( $p=0.018$ for trend). Participants in the highest tertile had a median change (IQR) in A1C of $-1.25 \%(-0.6$ to $-3.1 \%)$ compared with $-0.8 \%(-0.3 \%$ to $-2 \%)$ and $-0.5 \%(-0.2 \%$ to $-1.2 \%)$ in the middle and lowest tertiles, respectively ( $p=0.048$ for trend). The association between change in body weight and SMBG frequency remained significant after adjusting for age, sex, baseline body mass index, diabetes duration, and use of insulin therapy. Conclusions Increased frequency of SMBG during IMWM is associated with significantly better weight loss and improvement of A1C in patients with T2D and obesity. These findings may suggest future clinical recommendations aimed at increasing SMBG frequency to achieve the most favorable outcomes.

\section{INTRODUCTION}

Diabetes prevalence continues to rise globally for all age groups as researchers projected the number of patients with diabetes to double from 171 to 366 million between the years 2000 and 2030. ${ }^{1}$ The parallel rapid increase in prevalence of obesity in Western societies

\section{Significance of this study}

What is already known about this subject?

- Self-monitoring of blood glucose (SMBG) is helpful in providing biofeedback to assess real-time effects of lifestyle changes.

- The optimal frequency of SMBG in patients with type 2 diabetes (T2D) and obesity has been debated.

What are the new findings?

- Increased SMBG frequency in patients with T2D and obesity during intensive weight management is associated with significantly better weight loss and A1C improvement

How might these results change the focus of research or clinical practice?

- Increasing SMBG frequency in patients with T2D and obesity during intensive weight management should be considered in future recommendations.

further complicates the situation where nearly $87.5 \%$ of patients with type 2 diabetes (T2D) are either overweight or obese. ${ }^{2}$ Interventional studies in patients with combined T2D and obesity have shown that dietary intervention and increased physical activity can lead to weight reduction and significant improvements in glycemic control. Currently, lifestyle modifications and nutrition therapy are recommended as the first-line treatment for T2D. ${ }^{3}{ }^{4}$ However, patient adherence to lifestyle changes is a major challenge in realworld clinical practice. Lifestyle modifications are particularly difficult to achieve in many patients without accompanying realtime biofeedback to keep them motivated. Self-monitoring of blood glucose (SMBG) was introduced in 1971 and has been a valuable tool for providing feedback on glycemic control. ${ }^{5}$ SMBG revolutionized diabetes 
management, particularly in patients treated with intensive insulin therapy (IIT), requiring them to test 6-10 (or more) times per day. ${ }^{6-9}$ Such high frequency of SMBG in patients with type 1 diabetes on IIT was shown to be associated with a greater reduction in A1C and lower incidence of complications. ${ }^{4610}$ While the American Diabetes Association emphasizes the importance of frequent SMBG in patients on IIT, it clearly states the lack of evidence on clinical utility of specific SMBG frequency in patients with T2D treated with oral antihyperglycemic agents and/or basal insulins. ${ }^{8}$

Several randomized controlled trials (RCT) debated the utility of frequent SMBG in non-insulin-treated patients with T2D. It was suggested that integrating feedback from SMBG into clinical and lifestyle decisions may help in achieving glycemic targets in these patients. ${ }^{8}$ A meta-analysis of 15 RCTs showed that in non-insulin-treated patients with T2D, the use of SMBG was associated with greater reduction in A1C compared with non-SMBG. ${ }^{11}$ Bosi et alfound that use of a structured SMBG plan led to improved glycemic control among non-insulin-treated patients with T2D compared with patients who did not follow a structured SMBG plan. ${ }^{12}$ A more recent meta-analysis concluded that using structured SMBG data to adjust diabetes medications was tied to greater A1C reduction in non-insulin-treated patients with T2D. ${ }^{13}$ Although Martin et al showed that use of SMBG was associated with lower event rates of stroke and myocardial infarction among patients with T2D compared with non-SMBG users, blood pressure and lipid profile were not different in SMBG users compared with non-SMBG users. ${ }^{14}$ Therefore, data are lacking on whether more frequent SMBG has any impact on body weight, glycemic control, and cardiovascular disease (CVD) risk factors during short-term intensive multidisciplinary weight management (IMWM) programs in real-world clinical practice among patients with T2D and obesity. 8 15-19

We aimed to investigate the relationship between frequency of SMBG and changes in body weight, glycemic control, and CVD risk factors in patients with T2D and obesity enrolled in an IMWM program.

\section{METHODS}

\section{The IMWM program}

The Weight Achievement and Intensive Treatment (Why WAIT) is a 12-week IMWM program designed for patients with diabetes and obesity in real-world clinical practice. It was created in 2005 and has been delivered since then at a tertiary medical center in Boston, MA. Participants enrolled in the program should have a body mass index (BMI) of $30-45 \mathrm{~kg} / \mathrm{m}^{2}$ and be able to exercise. Qualified patients are enrolled in groups of 12-15 participants. Interventions are conducted weekly at the center in 2-hour group sessions over 12 consecutive weeks. All services provided in the Why WAIT program are classified as reimbursable and participation in the program is covered by most insurance plans. A detailed description of the program was previously published..$^{20-22}$ We will briefly outline the four essential components of the program.

\section{Medication adjustments}

Weight gain-promoting medications were substituted, whenever possible, with weight neutral or weight loss-promoting medications. ${ }^{23}$ Insulin therapy was used by $45 \%$ of past participants. At the beginning of the program, insulin doses were reduced by $20 \%-30 \%$ for patients with $\mathrm{A} 1 \mathrm{C}<7.5 \%$ but remained the same for patients with $\mathrm{A} 1 \mathrm{C}$ $\geq 7.5 \%$ then adjusted during the program on a weekly basis after careful reviewing of SMBG, food, and exercise logs. Patients who were unable to follow the medication adjustments plan were excluded to avoid the risk of severe hypoglycemia during weight reduction. Patients were medically evaluated for $30 \mathrm{~min}$ at weeks 4 and 8 by a nurse practitioner and at week 12 by a diabetologist.

\section{Structured medical nutrition therapy}

A registered dietitian provided participants with hypocaloric meal plans based on their age, sex, typical caloric intake, and physical activity. Carbohydrates made up $\sim 40 \%-45 \%$ of daily calories, fat $<35 \%$ with saturated fat $<10 \%, 1-1.5 \mathrm{~g} / \mathrm{kg}$ of adjusted body weight from protein, and $14 \mathrm{~g}$ of fiber per 1000 calories.

\section{Exercise intervention}

An exercise physiologist (EP) created individualized exercise plans based on each participant's health status and exercise capacity in addition to a weekly $60 \mathrm{~min}$ group exercise sessions under EP supervision. During the program, participants were instructed to increase their exercise duration and frequency from $20 \mathrm{~min} 4$ days/ week to $60 \mathrm{~min} 5-6$ days/week.

\section{Behavioral intervention}

Clinical psychologists and behavioral therapists used validated cognitive-behavioral therapeutic methods for weight management during once-weekly group behavioral support sessions. ${ }^{2425}$ This included: behavioral goal setting, self-monitoring of food intake and exercise, stimulus control techniques, and relapse prevention. ${ }^{2425}$

Didactic group education sessions were conducted weekly for $30 \mathrm{~min}$ and were led by a diabetologist, an EP, a registered dietitian, or clinical psychologist during the 12-week IMWM program. Each session discussed a different topic related to weight and diabetes management.

\section{Self-monitoring of blood glucose}

Irrespective of insulin use, participants in the Why WAIT program were encouraged to self-monitor their blood glucose using a personal glucometer on a daily basis before each meal, at bed time, before and after exercise, occasionally 2-3hours after meals, and when they feel their blood glucose is low or high. Each week, participants were asked to bring their personal glucometers to the 
medical center. SMBG data from the glucometers were synced to a cloud-based diabetes management system at an in-office kiosk (Glooko, Mountain View, CA, USA). Glooko is a telemonitoring system that allows patients to upload their SMBG data to the cloud and share it with their diabetes care team. SMBG data were transferred to an endocrinologist-accessed web cloud (population tracker) and were used by the program providers to make weekly informed therapeutic decisions in adjusting participants' antihyperglycemic medications as deemed necessary.

\section{Study subjects and design}

Due to the retrospective nature of this study, a waiver of the consent process was granted by the Committee on Human Studies (CHS) at the Joslin Diabetes Center (CHS waiver number 2018-01). We retrospectively evaluated 63 adult patients with T2D and obesity who were enrolled in the IMWM program between May 2016 and April 2018. Twenty-one patients did not upload or had incomplete SMBG data during the 12-week program and were excluded from the study. A total of 42 patients (67\%) transmitted complete SMBG data for the 12 weeks' duration of the program and were included in the analysis (mean age $57 \pm 9$ years, females $50 \%$, diabetes duration $10 \pm 8$ years, body weight of $107.5 \pm 21 \mathrm{~kg}$, BMI $36 \pm 6 \mathrm{~kg} / \mathrm{m}^{2}$, A1C 7.8\% $\pm 1.4 \%$, and $45 \%$ were treated with insulin). We divided participants in ordered distribution into tertiles based on average frequency of SMBG over 12 weeks with each tertile containing 14 participants. Demographic and clinical data at baseline, during the program, and at 12 weeks were collected from electronic medical records. Table 1 shows the baseline characteristics of study tertiles.

Table 1 Demographic and baseline characteristics of study tertiles

\begin{tabular}{|c|c|c|c|c|}
\hline & $\begin{array}{l}\text { Lowest tertile } \\
(n=14)\end{array}$ & $\begin{array}{l}\text { Middle tertile } \\
(n=14)\end{array}$ & $\begin{array}{l}\text { Highest tertile } \\
(n=14)\end{array}$ & P value* \\
\hline Age (years) & $58.7(9)$ & $56(9)$ & $55.5(8.5)$ & 0.6 \\
\hline Female sex (\%) & 42.8 & 42.8 & 64.3 & 0.4 \\
\hline \multicolumn{5}{|l|}{ Race/ethnicity (\%) } \\
\hline Non-Hispanic White & 42.8 & 71.4 & 35.7 & 0.1 \\
\hline African-American & 7.2 & 7.2 & 7.2 & 1 \\
\hline Asian & 0 & 0 & 0 & - \\
\hline Hispanic & 0 & 0 & 0 & - \\
\hline Other/not reported & 50 & 21.4 & 57.1 & 0.1 \\
\hline Diabetes duration (years) & $11.5(8)$ & $11(9)$ & $9(7.3)$ & 0.6 \\
\hline Weight (kg) & $107.6(20.3)$ & $107.4(19.2)$ & $107.4(24)$ & 0.9 \\
\hline Body mass index $\left(\mathrm{kg} / \mathrm{m}^{2}\right)$ & $36.5(6.5)$ & $34.5(4.5)$ & $37.4(5.9)$ & 0.4 \\
\hline A1C (\%) & $7.5(1.0)$ & $8.0(1.5)$ & $8.0(1.6)$ & 0.6 \\
\hline Use of insulin therapy (\%) & 42.9 & 35.7 & 57.1 & 0.5 \\
\hline Weight-adjusted insulin dose (units/kg/day) $\dagger$ & $0.49(0.3)$ & $0.85(0.4)$ & $0.44(0.3)$ & 0.1 \\
\hline \multicolumn{5}{|l|}{ Other diabetes medications (\%) } \\
\hline Metformin & 93 & 64 & 86 & 0.1 \\
\hline SFUs & 21 & 7 & 14 & 0.5 \\
\hline DPP-4 inhibitors & 0 & 0 & 14 & 0.1 \\
\hline SGLT-2 inhibitors & 50 & 79 & 57 & 0.3 \\
\hline GLP-1 analogs & 64 & 57 & 50 & 0.7 \\
\hline Systolic blood pressure $(\mathrm{mm} \mathrm{Hg})$ & $129(15)$ & $129(15)$ & $134(17)$ & 0.6 \\
\hline Diastolic blood pressure $(\mathrm{mm} \mathrm{Hg})$ & $77(8)$ & $77(7)$ & $79(6)$ & 0.6 \\
\hline Total cholesterol (mg/dL) & $144(21)$ & $164(34)$ & $173(40)$ & 0.08 \\
\hline LDL-cholesterol (mg/dL) & $74(17)$ & $88(33)$ & $88(26)$ & 0.3 \\
\hline HDL-cholesterol (mg/dL) & $48(12)$ & $46(11)$ & $56(16)$ & 0.1 \\
\hline Triglycerides (mg/dL) & $113(30)$ & $188(226)$ & $150(82)$ & 0.4 \\
\hline
\end{tabular}

Data are mean (SD) or \%.

*One-way analysis of variance (ANOVA) or Pearson's $\chi^{2}$ test.

†For insulin-treated subjects.

DPP, dipeptidyl peptidase; GLP, glucagon-like-peptide; HDL, high-density lipoprotein; LDL, low-density lipoprotein; SFU, sulfonylurea; SGLT, sodium-glucose transport proteins. 


\section{Statistical analysis}

Demographic and baseline characteristics were evaluated using descriptive statistics. Continuous variables are reported as mean \pm SD or median (IQR) as appropriate for their distribution as determined by Shapiro-Wilk test. Categorical variables are presented as percentages. The descriptive characteristics of the three tertiles were compared using one-way analysis of variance for continuous variables, and Pearson's $\chi^{2}$ test for categorical variables. The study outcomes were calculated as end of IMWM program minus baseline values. A non-parametric test for trend across ordered tertiles, an extension of the Wilcoxon rank-sum test, was used to explore the relationship between the tertile of SMBG frequency and change in metabolic outcomes. Univariate and multivariable linear regressions were used to investigate the association between SMBG frequency and changes in body weight and A1C. A two-sided $p$ value $<0.05$ was considered statistically significant. Statistical analysis was conducted using STATA Special Edition V.15.0 for Windows (StataCorp, College Station, Texas, USA, 2017).

\section{RESULTS}

\section{Characteristics of study tertiles}

At baseline, mean body weight was $107.6 \pm 20.3 \mathrm{~kg}$ in the lowest tertile of SMBG frequency, $107.4 \pm 19.2 \mathrm{~kg}$ in the middle tertile, and $107.4 \pm 24 \mathrm{~kg}$ in the highest tertile. A1C was $7.5 \% \pm 1.0 \%, 8.0 \% \pm 1.5 \%$, and $8.0 \% \pm 1.6 \%$, respectively. At baseline, there were no significant differences among the three tertiles in age, sex, race, duration of diabetes, insulin use, A1C, body weight, or BMI. Nine patients $(64.3 \%)$ in the lowest tertile, $11(78.6 \%)$ in the middle tertile, and $10(71.4 \%)$ in the highest tertile attended 11-12 sessions (92\%-100\%) of the IMWM program. The remaining patients attended 8-10 sessions ( $p=0.7$ between tertiles) .

\section{Frequency of SMBG in study tertiles}

Mean (range) SMBG frequency was 2.3 (1.1-2.9) times per day in the lowest tertile, 3.4 (3-3.9) times per day in the middle tertile, and 5 (4-7.7) times per day in the highest tertile. Only one participant in the highest tertile performed SMBG on average $>7$ times per day.

\section{Changes from baseline to 12 weeks in SMBG frequency tertiles \\ Frequency of SMBG and change in body weight}

After 12 weeks, higher frequency of SMBG was associated with significantly higher magnitude of weight loss in comparison to lower frequency of testing (table 2). Participants in the highest tertile achieved a median change (IQR) in body weight of $-10.4 \mathrm{~kg}(-7.6$ to $-14.4 \mathrm{~kg})$ compared with $-8.3 \mathrm{~kg}(-5.2$ to $-12.2 \mathrm{~kg})$, and $-6.9 \mathrm{~kg}$ $(-4.2$ to $-8.9 \mathrm{~kg})$ in the middle and lowest tertiles, respectively ( $\mathrm{p}=0.018$ for linear trend across tertiles). This translated to a BMI change of $-3.9 \mathrm{~kg} / \mathrm{m}^{2}\left(-2.8\right.$ to $\left.-4.9 \mathrm{~kg} / \mathrm{m}^{2}\right)$, $-2.7 \mathrm{~kg} / \mathrm{m}^{2}\left(-1.6\right.$ to $\left.-3.9 \mathrm{~kg} / \mathrm{m}^{2}\right)$, and $-2.5 \mathrm{~kg} / \mathrm{m}^{2}(-1.5$ to $\left.-3.3 \mathrm{~kg} / \mathrm{m}^{2}\right)$, respectively $(\mathrm{p}=0.012$ for linear trend across tertiles).

To confirm these findings, we examined the association between SMBG frequency and the main outcome measure of change in body weight in the total cohort $(n=42)$. Linear regression analyses revealed a significant association between SMBG frequency and change in body weight over 12 weeks (table 3 ). In multivariable analyses, this association remained significant after adjusting for age, sex, and baseline BMI (model 1). After adjusting for age, sex, baseline BMI, and diabetes duration, the results were similar to the unadjusted model (model 2). Furthermore, the association remained significant after adjusting for age, sex, baseline BMI, diabetes duration, and use of insulin therapy (model 3).

Table 2 Changes in metabolic parameters at 12 weeks in study tertiles

\begin{tabular}{|c|c|c|c|c|}
\hline & Lowest tertile $(n=14)$ & Middle tertile $(n=14)$ & Highest tertile $(n=14)$ & $\mathbf{P}$ value† \\
\hline Body weight (kg) & $-6.9(-4.2$ to -8.9$)$ & $-8.3(-5.2$ to -12.2$)$ & $-10.4(-7.6$ to -14.4$)$ & $0.018^{*}$ \\
\hline BMI $\left(k g / m^{2}\right)$ & $-2.5(-1.5$ to -3.3$)$ & $-2.7(-1.6$ to -3.9$)$ & $-3.9(-2.8$ to -4.9$)$ & $0.012^{*}$ \\
\hline $\mathrm{A} 1 \mathrm{C}(\%)$ & $-0.5(-0.2$ to -1.2$)$ & $-0.8(-0.3$ to -2$)$ & $-1.25(-0.6$ to -3.1$)$ & $0.048^{*}$ \\
\hline Systolic blood pressure (mm Hg) & $1(-16$ to 6$)$ & $-3.5(-13$ to 8$)$ & $-12(-17$ to -5$)$ & 0.1 \\
\hline Diastolic blood pressure (mm Hg) & 0.5 (-4 to 4$)$ & $-3.5(-10$ to 0$)$ & $-5(-10$ to 0$)$ & 0.1 \\
\hline Total cholesterol (mg/dL) & $-12(-18.5$ to -4.5$)$ & $-16(-21$ to 5$)$ & $-19(-37$ to -8$)$ & 0.2 \\
\hline LDL-cholesterol (mg/dL) & $-11.5(-15$ to 1$)$ & $-0.5(-13$ to 13$)$ & $-7(-20$ to 5$)$ & 0.7 \\
\hline HDL-cholesterol (mg/dL) & 2 (0 to 8$)$ & $3.5(-1$ to 4$)$ & -2 ( -5 to 2$)$ & 0.06 \\
\hline Triglycerides (mg/dL) & $-12(-28$ to 14$)$ & $-31.5(-55$ to -10$)$ & $-30(-75$ to -13$)$ & 0.08 \\
\hline $\begin{array}{l}\text { Weight-adjusted insulin dose (units/kg/ } \\
\text { day) } \ddagger\end{array}$ & $\begin{array}{l}-0.18(-0.34 \text { to } \\
-0.12)\end{array}$ & $\begin{array}{l}-0.38(-0.44 \text { to } \\
-0.23)\end{array}$ & $-0.2(-0.8$ to 0.17$)$ & 0.5 \\
\hline
\end{tabular}

Data are median (IQR).

${ }^{*} \mathrm{P}<0.05$.

†Non-parametric test for trend across ordered groups, an extension of the Wilcoxon rank-sum test.

fFor insulin-treated subjects.

BMI, body mass index; HDL, high-density lipoprotein; LDL, low-density lipoprotein. 
Table 3 Association between change in body weight and self-monitoring of blood glucose (SMBG)

\begin{tabular}{|c|c|c|c|c|c|c|c|c|}
\hline & \multicolumn{2}{|l|}{ Crude } & \multicolumn{2}{|l|}{ Model 1} & \multicolumn{2}{|l|}{ Model 2} & \multicolumn{2}{|l|}{ Model 3} \\
\hline & $\beta(95 \% \mathrm{Cl})$ & $P$ value & $\beta(95 \% \mathrm{Cl})$ & $P$ value & $\beta(95 \% \mathrm{Cl})$ & $P$ value & $\beta(95 \% \mathrm{Cl})$ & $P$ value \\
\hline $\begin{array}{l}\text { SMBG } \\
\text { frequency } \\
\text { (times per day) }\end{array}$ & $\begin{array}{l}-1.044 \\
(-2.062 \text { to } \\
-0.272)\end{array}$ & 0.044 & $\begin{array}{l}-0.972 \\
(-1.934 \text { to } \\
-0.011)\end{array}$ & 0.048 & $\begin{array}{l}-1.013 \\
(-1.997 \text { to } \\
-0.0294)\end{array}$ & 0.044 & $\begin{array}{l}-1.117 \\
(-2.158 \text { to } \\
-0.0757)\end{array}$ & 0.036 \\
\hline
\end{tabular}

Model 1 is adjusted for age, sex, and baseline body mass index (BMI).

Model 2 is adjusted for age, sex, baseline BMI and diabetes duration.

Model 3 is adjusted for age, sex, baseline BMI, diabetes duration and use of insulin therapy.

\section{Frequency of SMBG and change in A1C}

Similarly, higher frequency of SMBG was associated with significantly lower $\mathrm{A} 1 \mathrm{C}$ in comparison to lower frequency of testing. Median change (IQR) of A1C was $-1.25 \%$ $(-0.6 \%$ to $-3.1 \%)$ in the highest tertile compared with $-0.8 \%(-0.3 \%$ to $-2 \%)$ and $-0.5 \%(-0.2 \%$ to $-1.2 \%)$ in the middle and lowest tertiles, respectively $(\mathrm{p}=0.048$ for linear trend across tertiles) (figure 1). In our cohort, changes in A1C at 12 weeks were significantly associated

\section{A}

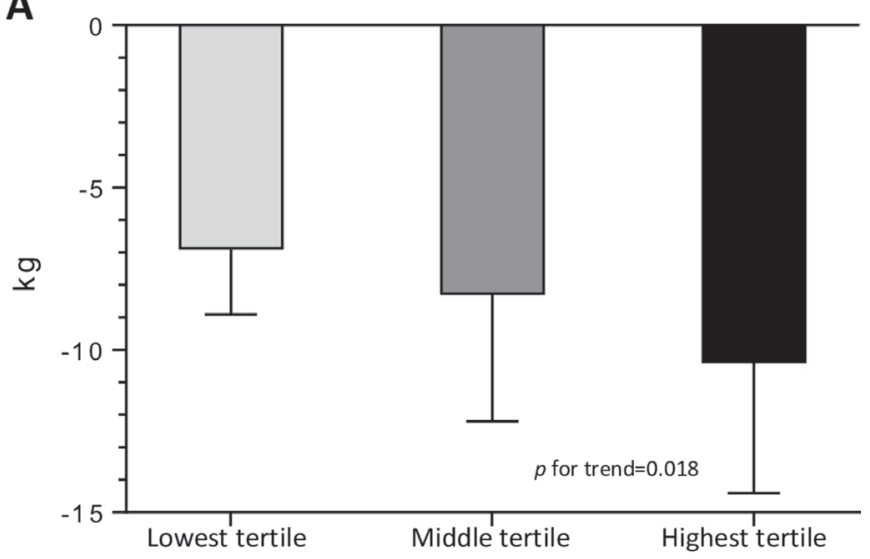

B

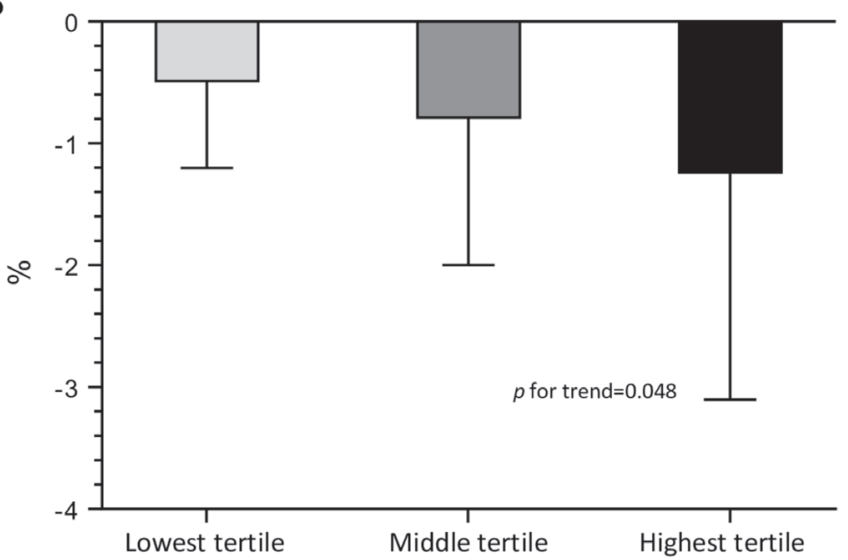

Figure 1 Median change (IQR) in (A) body weight and (B) A1C across SMBG tertiles at 12 weeks . $n=14$ in each tertile. Mean (range) SMBG frequency was 2.3 (1.1 to 2.9) times per day in the lowest tertile, 3.4 (3 to 3.9) times per day in the middle tertile, and 5 (4 to 7.7 ) times per day in the highest tertile. with baseline A1C levels $\left(\mathrm{R}^{2}=0.76, \mathrm{p}<0.0001\right)$. Although the weak association between SMBG frequency and reduction in A1C did not reach statistical significance in simple linear regression $\left(\mathrm{R}^{2}=0.18, \mathrm{p}=0.06\right)$ (table 4$)$, this association was strengthened after adjusting for baseline A1C (adjusted $\mathrm{R}^{2}=0.77, \mathrm{p}<0.05$ ) (model 1). Furthermore, this association remained significant after adjusting for baseline A1C, age, sex and diabetes duration (model 2) as well as use of insulin therapy (model 3 ).

Among insulin-treated patients, $5(62.5 \%)$ in the highest tertile stopped insulin by the end of the 12-week IMWM program compared with $1(20 \%)$ and $1(16.7 \%)$ in the middle and lowest tertiles, respectively $(\mathrm{p}=0.14$ between tertiles).

\section{Frequency of SMBG and change in CVD risk factors}

Changes in blood pressure and lipid profile showed no significant relation to tertile of SMBG frequency (table 2).

\section{DISCUSSION}

To our knowledge, this study is among the first to evaluate the relationship between the frequency of SMBG and body weight, glycemic control, and CVD risk factors in patients with T2D and obesity during an IMWM program. After dividing participants into three tertiles based on the frequency of daily SMBG, we found a significant relationship between SMBG frequency and changes in body weight and $\mathrm{A} 1 \mathrm{C}$ over 12 weeks, with reductions in body weight and improvement in A1C being higher in those who frequently monitored their blood glucose irrespective of insulin use. These findings indicate a possible increased benefit by recommending higher frequency of SMBG during IMWM programs. Although attendance of the IMWM program sessions was similar across study tertiles, this might not reflect actual active engagement in the different components of the IMWM program. The results of this study may be attributed to patients' improved exercise behavior and adherence to the recommended dietary plan consequent to real-time feedback from SMBG during IMWM in patients with T2D and obesity. ${ }^{26}$ Although participants enrolled in the Why WAIT program were generally testing their blood glucose more frequently than average patients in diabetes clinics, providing them with additional strips and/or justifying the necessity for frequent glucose testing with their 
Table 4 Association between change in A1C and self-monitoring of blood glucose (SMBG)

\begin{tabular}{|c|c|c|c|c|c|c|c|c|}
\hline & \multicolumn{2}{|l|}{ Crude } & \multicolumn{2}{|l|}{ Model 1} & \multicolumn{2}{|l|}{ Model 2} & \multicolumn{2}{|l|}{ Model 3} \\
\hline & B (95\% Cl) & $P$ value & $\beta(95 \% \mathrm{Cl})$ & $P$ value & $\beta(95 \% \mathrm{Cl})$ & $P$ value & $\beta(95 \% \mathrm{Cl})$ & $P$ value \\
\hline $\begin{array}{l}\text { SMBG frequency } \\
\text { (times per day) }\end{array}$ & $\begin{array}{l}-0.241 \\
(-0.496 \text { to } \\
0.013)\end{array}$ & 0.06 & $\begin{array}{l}-0.131 \\
(-0.261 \text { to } \\
-0.0007)\end{array}$ & 0.049 & $\begin{array}{l}-0.158 \\
(-0.276 \text { to } \\
-0.041)\end{array}$ & 0.009 & $\begin{array}{l}-0.182 \\
(-0.303 \text { to } \\
-0.062)\end{array}$ & 0.004 \\
\hline
\end{tabular}

Model 1 is adjusted for baseline A1C.

Model 2 is adjusted for baseline A1C, age, sex, and diabetes duration.

Model 3 is adjusted for baseline A1C, age, sex, diabetes duration and use of insulin therapy.

insurance plans clearly added further benefits during the intervention.

In this cohort, the findings of a strong trend toward higher magnitude of weight loss and reduction in BMI with more frequent SMBG (table 2) were confirmed in multivariate analyses accounting for important confounders including age, sex, baseline BMI, diabetes duration, and use of insulin therapy (table 3 ).

It is important to note that participants in the middle and highest tertiles of SMBG frequency had a mean baseline $\mathrm{A} 1 \mathrm{C}$ of $8.0 \% \pm 1.5 \%$ and $8.0 \% \pm 1.6 \%$, respectively, compared with $7.5 \% \pm 1.0 \%$ for peers in the lowest tertile. Although we initially found a weak trend toward better glycemic control with increased frequency of SMBG, the marginal $\mathrm{p}$ for trend (0.048) (table 2) mirrored the absence of a statistically significant association in the unadjusted linear regression analysis $(\mathrm{p}=0.06)$ (table 4$)$. However, after adjusting for baseline $\mathrm{A} 1 \mathrm{C}$, the association between SMBG frequency and reduction in $\mathrm{A} 1 \mathrm{C}$ reached statistical significance indicating confounding effect of baseline $\mathrm{AlC}$ on the magnitude of improvement in glycemic control over the 12-week IMWM program. This is consistent with findings from a meta-analysis of nine RCTs that evaluated the benefits of SMBG on glycemic control in patients with T2D where A1C significantly improved in the subgroup of patients whose mean baseline $\mathrm{A} 1 \mathrm{C}$ was $\geq 8.0 \%$ in contrast to those with baseline $\mathrm{A} 1 \mathrm{C}$ $<8.0 \%$ o. ${ }^{27}$ Park $e t$ al showed that perception of time has an effect on glycemic variability in patients with $\mathrm{T} 2 \mathrm{D},{ }^{28}$ however, it is unknown if the perception of SMBG values has similar effects on long-term glycemic control.

In this cohort, we did not observe any relationship between tertile of SMBG frequency and changes in blood pressure or lipid profile, which was not a surprise since all participants showed improvement in these cardiovascular risk factors by the end of the 12-week program.

This study has several limitations including its retrospective design, small sample size, the lack of a control group, and being conducted at a single tertiary care center. Retrospective design might help our purpose in reflecting the reality of frequency of testing in real practice when more testing is recommended at the beginning. It also prevents dilution of results if poor adherence non-intentionally plagued the high-testing groups in the prospective design. Increasing the sample size may increase the power of the study and limit the margin of errors. Having a control group may add some value, but the main purpose of the study is to compare the impact of SMBG frequency within a cohort exposed to the same IMWM program. This IMWM program requires a considerable time commitment and financial resources from its participants which may limit the generalizability of these results. However, study tertiles had similar racial/ethnic distribution. Furthermore, scientifically known confounders were adjusted for in our statistical analyses in a systematic way to help with interpreting the results. Data on physical and mental quality of life and barriers to performing SMBG and/or uploading SMBG data were lacking due to the retrospective design of the study. However, despite these limitations, our study suggests that increased SMBG frequency may be important during IMWM to obtain maximal weight loss and glycemic improvement and may warrant the use of continuous glucose monitors in patients with T2D and obesity during intensive weight reduction irrespective of insulin use. This assumption may need to be confirmed in a randomized clinical study that evaluates the effect of different SMBG frequencies on body weight and glycemic control in patients with T2D and obesity during an IMWM program, and puts into consideration the cost-effectiveness of using a continuous glucose monitor during weight loss. While previous studies compared SMBG with non-SMBG users with T2D and evaluated the change in A1C among patients with T2D who followed a structured compared with a non-structured SMBG plan, ${ }^{11} 12$ our study is the first to describe the relationship between ascending frequencies of SMBG and the direction of change in body weight during an IMWM program. The real-world nature of this study helps minimize the discrepancies in effectiveness that are frequently noted between clinical trials and realworld clinical practice. ${ }^{29}$

In conclusion, this study showed that patients with T2D and obesity who engage in more frequent SMBG during a 12-week IMWM program achieve more favorable weight loss outcomes and greater reductions in A1C. This association remained significant after adjusting for age, sex, baseline BMI and A1C, diabetes duration, and use of insulin therapy. These results suggest possible future recommendations for increasing SMBG frequency in patients with T2D during IMWM to reach optimal outcomes. 
Acknowledgements The authors thank the clinical and administrative staff of the Why WAIT program at Joslin Diabetes Center.

Contributors ST designed the study, collected data, conducted statistical analysis, and drafted the manuscript. NM collected data and drafted the manuscript. AM and SA collected data and reviewed and edited the manuscript. DMP contributed to the statistical analysis and reviewed and edited the manuscript. MWT collected data, contributed to the introduction section, and reviewed and edited the manuscript. $\mathrm{OH}$ designed the study, supervised the work, and reviewed and edited the manuscript. ST and $\mathrm{OH}$ are the guarantors of this work and take responsibility for its integrity and the accuracy of data analysis. All authors approved the final version of the manuscript.

Funding This is an investigator-initiated study funded internally at Joslin Diabetes Center.

Competing interests $\mathrm{OH}$ receives research support from the National Dairy Council; consults for Merck, Sanofi-Aventis and Abbott Nutrition; on the advisory board of Astra Zeneca and is a shareholder of Healthimation. ST is shareholder of Amarin. None of these entities supported this research in part or total.

Patient consent for publication Not required.

Ethics approval The Joslin Diabetes Center Committee on Human Studies.

Provenance and peer review Not commissioned; externally peer reviewed.

Data availability statement No additional data are available.

Open access This is an open access article distributed in accordance with the Creative Commons Attribution Non Commercial (CC BY-NC 4.0) license, which permits others to distribute, remix, adapt, build upon this work non-commercially, and license their derivative works on different terms, provided the original work is properly cited, appropriate credit is given, any changes made indicated, and the use is non-commercial. See: http://creativecommons.org/licenses/by-nc/4.0/.

\section{REFERENCES}

1. Wild S, Roglic G, Green A, et al. Global prevalence of diabetes: estimates for the year 2000 and projections for 2030. Diabetes Care 2004:27:1047-53.

2. Control CfD, Prevention. National diabetes statistics report, 2017. Atlanta, GA: Centers for Disease Control and Prevention, 2017.

3. Pi-Sunyer X, Blackburn G, Brancati FL, et al. Reduction in weight and cardiovascular disease risk factors in individuals with type 2 diabetes: one-year results of the look ahead trial. Diabetes Care 2007;30:1374-83.

4. American Diabetes Association. 4. Lifestyle management: standards of medical care in diabetes-2018. Diabetes Care 2018;41(Suppl 1):S38-S50.

5. El-Laboudi A, Oliver NS, Cass A, et al. Use of microneedle array devices for continuous glucose monitoring: a review. Diabetes Technol Ther 2013;15:101-15.

6. Walford S, Gale EA, Allison SP, et al. Self-Monitoring of bloodglucose. improvement of diabetic control. Lancet 1978;1:732-5.

7. Sönksen PH, Judd SL, Lowy C. Home monitoring of blood-glucose. method for improving diabetic control. Lancet 1978;1:729-32.

8. American Diabetes Association. 6. Glycemic targets: standards of medical care in diabetes-2018. Diabetes Care 2018;41(Suppl 1):S55-64.

9. Newman JD, Turner APF. Home blood glucose biosensors: a commercial perspective. Biosens Bioelectron 2005;20:2435-53.

10. Nathan DM, Genuth S, Lachin J, et al. The effect of intensive treatment of diabetes on the development and progression of longterm complications in insulin-dependent diabetes mellitus. $N$ Engl J Med 1993;329:977-86.
11. Allemann S, Houriet C, Diem P, et al. Self-Monitoring of blood glucose in non-insulin treated patients with type 2 diabetes: a systematic review and meta-analysis. Curr Med Res Opin 2009;25:2903-13.

12. Bosi E, Scavini M, Ceriello A, et al. Intensive structured selfmonitoring of blood glucose and glycemic control in noninsulintreated type 2 diabetes: the PRISMA randomized trial. Diabetes Care 2013;36:2887-94.

13. Mannucci E, Antenore A, Giorgino F, et al. Effects of structured versus unstructured self-monitoring of blood glucose on glucose control in patients with non-insulin-treated type 2 diabetes: a metaanalysis of randomized controlled trials. J Diabetes Sci Technol 2018;12:183-9.

14. Martin S, Kolb H, Schneider B, et al. Myocardial infarction and stroke in early years after diagnosis of type 2 diabetes: risk factors and relation to self-monitoring of blood glucose. Diabetes Technol Ther 2009;11:234-41.

15. Farmer A, Wade A, Goyder E, et al. Impact of self monitoring of blood glucose in the management of patients with non-insulin treated diabetes: open parallel group randomised trial. BMJ $2007 ; 335$

16. O'Kane MJ, Bunting B, Copeland M, et al. Efficacy of self monitoring of blood glucose in patients with newly diagnosed type 2 diabetes (ESMON study): randomised controlled trial. BMJ 2008;336:1174-7.

17. Willett LR. ACP Journal Club. Meta-analysis: self-monitoring in non-insulin-treated type 2 diabetes improved $\mathrm{HbA} 1 \mathrm{c}$ by $0.25 \%$. Ann Intern Med 2012;156:JC6-12.

18. Malanda UL, Welschen LMC, Riphagen II, et al. Self-Monitoring of blood glucose in patients with type 2 diabetes mellitus who are not using insulin. Cochrane Database Syst Rev 2012;1.

19. Schütt M, Kern, W, Krause U, et al. Is the frequency of selfmonitoring of blood glucose related to long-term metabolic control? multicenter analysis including 24500 patients from 191 centers in Germany and Austria. Exp Clin Endocrinol Diabetes 2006;114:384-8.

20. Hamdy O, Mottalib A, Morsi A, et al. Long-Term effect of intensive lifestyle intervention on cardiovascular risk factors in patients with diabetes in real-world clinical practice: a 5-year longitudinal study. BMJ Open Diab Res Care 2017;5:e000259.

21. Hamdy $\mathrm{O}$, Carver $\mathrm{C}$. The why wait program: improving clinical outcomes through weight management in type 2 diabetes. Curr Diab Rep 2008;8:413-20.

22. Mottalib A, Tomah S, Hafida S, et al. Intensive multidisciplinary weight management in patients with type 1 diabetes and obesity: a one-year retrospective matched cohort study. Diabetes Obes Metab 2019;21:37-42.

23. Mitri J, Hamdy O. Diabetes medications and body weight. Expert Opin Drug Saf 2009;8:573-84.

24. Knowler WC, Barrett-Connor E, Fowler SE, et al. Reduction in the incidence of type 2 diabetes with lifestyle intervention or metformin. N Engl J Med 2002;346:393-403.

25. Wadden TA, Stunkard AJ. Handbook of obesity treatment. Guilford Press, 2002.

26. Bailey KJ, Little JP, Jung ME. Self-Monitoring using continuous glucose monitors with real-time feedback improves exercise adherence in individuals with impaired blood glucose: a pilot study. Diabetes Technol Ther 2016;18:185-93.

27. Poolsup N, Suksomboon N, Rattanasookchit S. Meta-Analysis of the benefits of self-monitoring of blood glucose on glycemic control in type 2 diabetes patients: an update. Diabetes Technol Ther 2009;11:775-84.

28. Park C, Pagnini F, Reece A, et al. Blood sugar level follows perceived time rather than actual time in people with type 2 diabetes. Proc Nat Acad Sci U S A 2016;113:8168-70.

29. Edelman SV, Polonsky WH. Type 2 diabetes in the real world: the elusive nature of glycemic control. Diabetes Care 2017;40:1425-32. 